\title{
Bridging the Gap: An Integrated Approach to Facilitating Foundational Learning of Neuroanatomy and Neurophysiology in Graduate-Level Speech-Language Pathology Coursework
}

\author{
Lisa A. Vinney \\ Illinois State University, lavinne@ilstu.edu \\ Jennine M.T. Harvey \\ Illinois State University, jmharv2@ilstu.edu \\ DOI: doi.org/10.30707/TLCSD1.2Vinney
}

Follow this and additional works at: https://ir.library.illinoisstate.edu/tlcsd

Part of the Speech Pathology and Audiology Commons

\section{Recommended Citation}

Vinney, Lisa A. and Harvey, Jennine M.T. (2017) "Bridging the Gap: An Integrated Approach to Facilitating Foundational Learning of Neuroanatomy and Neurophysiology in Graduate-Level Speech-Language Pathology Coursework," Teaching and Learning in Communication Sciences \& Disorders: Vol. 1: Iss. 2, Article 1.

DOI: doi.org/10.30707/TLCSD1.2Vinney

Available at: https://ir.library.illinoisstate.edu/tlcsd/vol1/iss2/1

This Scholarship of Teaching and Learning Research is brought to you for free and open access by ISU ReD: Research and eData. It has been accepted for inclusion in Teaching and Learning in Communication Sciences \& Disorders by an authorized editor of ISU ReD: Research and eData. For more information, please contact ISUReD@ilstu.edu. 


\title{
Bridging the Gap: An Integrated Approach to Facilitating Foundational Learning of Neuroanatomy and Neurophysiology in Graduate-Level Speech-Language Pathology Coursework
}

\begin{abstract}
The current study examined whether the integration of foundational neuroanatomy and neurophysiology content, across a pair of medically-based, disorder-specific courses (motor speech disorders and aphasia), promoted students' abilities to describe common neurological constructs and apply them to clinical cases. Specifically, student responses to case questions were rubric-scored following their completion of five neuroanatomy and neurophysiology online modules independently and after in-class instructional augmentation of each module's content. Students' own perceptions of this integrated curriculum were also surveyed and coded into themes. Rubric scores, evaluating content knowledge of the brainstem, spinal cord, and the neuron, significantly improved from post-module to after in-class augmentation of modules. Likewise, rubric scores, evaluating clinical application, significantly improved from post-module to after in-class augmentation of modules for the areas of the brain, brainstem, spinal cord, and the neuron. The majority of students also believed that the integrated pedagogical methods facilitated their knowledge and application of neuroanatomy and neurophysiology concepts in order to prepare them for core content in both classes.
\end{abstract}

\section{Keywords}

neuroanatomy, neurophysiology, integration, curricular design, case-based learning

\section{Cover Page Footnote}

The authors would like to acknowledge the Center for Teaching, Learning, and Technology at Illinois State University for funding this project via a Teaching Innovation Grant. 


\section{Silos in Speech-Language Pathology Education}

Graduate speech-language pathology (SLP) programs are often structured with curriculum in silos such that each category of communication disorder is discussed within its own course. Coverage of nine major subject areas (i.e., articulation, voice and resonance, fluency, hearing, swallowing, cognitive aspects of communication, receptive and expressive language, social aspects of communication, and augmentative and alternative communication) is required for SLP graduate programs to maintain accreditation (Council for Clinical Certification in Audiology and Speech-Language Pathology of the American Speech-Language-Hearing Association, 2013). Thus, SLP academic programs, in an effort to clearly comply with these standards, are typically designed such that one or two classes are focused on a single type of disorder that falls under each of the nine required areas. Unfortunately, this discipline-based model (Sankowsky, 1998) may lead to several issues affecting curricular efficiency as well as the quality of instruction and student learning. Specifically, it may limit opportunities for application of foundational information to complex clinical cases across practica and coursework experiences (Friberg \& Harbers, 2016; Jackson \& Woosley, 2009; Wilson, 2002). Because most communication disorders do not occur in isolation (Friberg \& Harbers, 2016), segmentation of classes into disorder types does not reflect what students will typically see in clinical practice. As a result, students may not recognize when, how, and why similar etiologies (i.e., neurological or anatomical deficits) lead to multiple communication disorders in the same individual. This is especially problematic because students may not learn how to make these connections on their own without explicit practice (Ambrose, Bridges, DiPietro, Lovett, \& Norman, 2010). Unfortunately, this kind of "practice" may not take place until students are completing advanced practica or already certified as speech-language pathologists. Additionally, this model often results in unneeded redundancy in which content common to many classes is retaught by multiple instructors. For example, neuroanatomy and neurophysiology underlying various disorders and conditions (motor speech, aphasia, traumatic brain injury, dysphagia) may be taught multiple times in specific disorder-based courses without any explicit discussion about how this information may relate across the curriculum and in clinical practice.

A development-based model (Sankowsky, 1998) may potentially inform and remedy these challenges by emphasizing how information in SLP coursework may be organized and applied. This model places particular emphasis on the expected outcomes of learning demonstrated by students at the conclusion of an educational program or class (Spady, 1994). Thus, specific learning objectives drive course design and curricular decisions (Fink, 2013). It could be argued that the overarching significant learning outcome of SLP graduate program coursework is to 
facilitate students to become competent clinicians who are able to apply foundational content to the assessment and treatment of complex communication disorders. Therefore, learning activities, feedback, and assessment techniques should be specifically linked to this outcome, and infused both within and across coursework.

Implementation of these components may challenge students, not only to remember and understand foundational information, but also apply it in clinically meaningful ways across case scenarios. While often times these forms of learning are considered hierarchical in nature (Bloom, 1956; Anderson \& Krathwohl, 2001), we suggest that these outcomes may be achieved via horizontal integration defined as "integration of knowledge and skills between clinical subjects" and vertical integration defined as the "integration of basic knowledge and skills in the clinical context" (Snyman \& Kroon, 2004, p. 26). Thus, horizontal integration involves the blending of foundational knowledge across subject areas (often within the same discipline) and vertical integration involves the application of that knowledge to clinical practice.

\section{Horizontal and Vertical Integration via Clinical Cases}

To provide students with opportunities for both horizontal and vertical integration during clinical training, many researchers and educators have proposed using case scenarios (Alsaggaf, Ali, Ayuob, Eldeek, \& El-Haggagy, 2010; Harman et al., 2015; Krockenberger, Bosward, \& Canfield, 2007). Case questions commonly challenge students to connect different types of foundational knowledge (i.e., horizontal integration) and then practically apply it to a real or fictional patient (i.e., vertical integration). Instruction that is case-based has reportedly facilitated gains in clinical skill development and the critical analysis and evaluation of various problem scenarios in fields such as medicine, dentistry, and other healthcare disciplines including dietetics, nursing, physical therapy, and SLP (Harden, 2000; Hassan, 2013; Howard, Stewart, Woodall, Kingsley, \& Ditmyer, 2009; Malik \& Malik, 2011; Harman et al., 2015; Kantar \& Massouh, 2015; Yoo \& Park, 2015; Loghmani, Bayliss, Strunk, \& Altenburger, 2011; Meilijson \& Katzenberger, 2015; Leahy et al., 2010 ). Further, activities that involve evaluation of cases via students from a variety of disciplines have led to both horizontal integration of foundational knowledge that is both intradisciplinary and interdisciplinary in nature (Trommelen, Heber, \& Nelson, 2014; Mathisen, Yates, \& Crofts, 2011; Holland, Roberts, Vanstewart, \& Wright, 1994). This is particularly relevant, as it may assist students in skillfully engaging in a collaborative, team-based approach during their future clinical practice. 
The Case for Horizontal and Vertical Integration of Neuroanatomy and Neurophysiology in SLP Education

We propose that explicit horizontal and vertical integration of neuroanatomy and neurophysiology information should take place across graduate-level SLP coursework. From the horizontal integration perspective, opportunities for intradisciplinary learning (i.e., connecting motor speech with aphasia and anatomy with physiology) should assist students in seeing how sub-areas of the SLP curriculum relate to each other. Likewise, from the vertical integration perspective opportunities for student to connect their foundational knowledge (neuroanatomy and neurophysiology) to higher levels of learning (i.e., application) should help them bridge the gap between the classroom and the clinic. Thus, when students interpret cases that display signs and symptoms of various communication disorders simultaneously (motor speech, aphasia, traumatic brain injury), vertical and horizontal integration should be facilitated. See Figure 1 for a visual representations of how horizontal and vertical integration applies to SLP with particular emphasis on motor speech disorders, aphasia, and neuroanatomy and physiology.

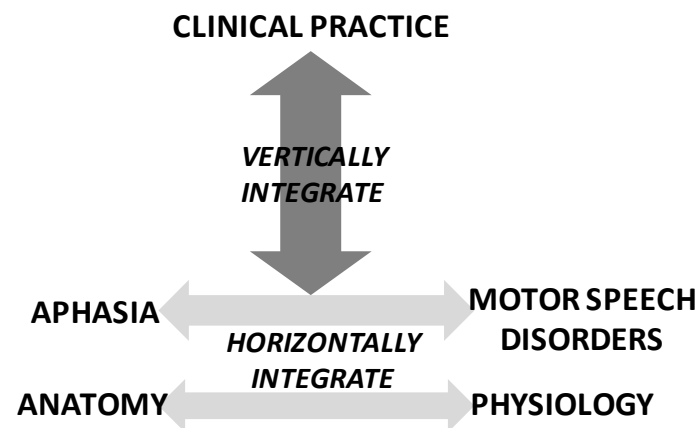

Figure 1: Horizontal integration addresses connections between types of foundational knowledge such as between anatomy and physiology or motor speech disorders and aphasia whereas vertical integration involves integrating lower levels of foundational knowledge. (potentially integrated at the horizontal level) clinically.

Unfortunately, research evidence indicates that SLP curriculum, designed to address neuroanatomy and neurophysiology, could be better integrated horizontally and vertically in order to most effectively address the overarching educational goal (i.e., to train competent clinicians) of clinical SLP programs. For example, in 
qualitative interviews with a small number of practicing speech-language pathologists, interviewees reported difficulty linking foundational neuroanatomy and neurophysiology information to clinical practice; noted redundancy in the dissemination of neuroanatomy and neurophysiology content throughout their academic programs; felt that they were to unable to truly apply neuroanatomy and neurophysiology content to clinical practice until working in the field; and noted difficulty making explicit links between foundational content and higher level clinical knowledge (Martin, Bessell, \& Scholten, 2014).

\section{Connecting Horizontal and Vertical Integration to a Cognitivist View of Learning}

To best address the deficits in horizontal and vertical integration in SLP curriculum, a focus on the cognitive processes underlying each is useful. In particular, horizontal integration and vertical integration focus on recall of information and its transfer (i.e., the application of information to specific contexts), respectively. A cognitivist view of learning, and in particular, a cognitive theory of multimedia learning, suggest that facilitation of students' recall of foundational information may be specifically facilitated via instruction that presents information in a meaningful and organized way, while also drawing attention to crucial concepts and away from less relevant material (Cooper, 1993, Ertmer \& Newby, 1993, Mayer, 1997, 2002, 2009). Because information that is visual (words and pictures) and auditory (narration), may be processed in separate sensory channels (each with finite processing capacity), recall of new information can be facilitated and cognitive load can be reduced when visual and auditory information are integrated coherently during multimedia instructional activities (Mayer \& Moreno, 2003; Mayer, 2009). If instruction facilitates the acquisition of information in these separate sensory channels such that it is integrated and rehearsed in working memory, and further encoded and retrieved from long-term memory, recall is likely to be facilitated (Mayer, 2009; Clark \& Harrelson, 2002). Thus, well-designed multimedia involves presenting visual and auditory information that guides the learner to select relevant conceptual information, decreases cognitive load by offering information with visuals and narration that can be reviewed at one's own pace, and facilitates effective encoding of information into long-term memory schemas.

Facilitation of students' transfer may be best aided by providing students with opportunities to apply foundational information to specific contexts. Thus, for transfer to occur, the learner needs to practice retrieving conceptual information from long-term memory and applying it to particular situations. Acquiring knowledge in the context of application has been thought to facilitate this cognitive 
process (Clark \& Harrelson, 2002). In particular, a case-based approach to learning has aided in facilitating transfer, over and above lecture and discussion (Harman et al., 2015; Loghmani et al., 2011; Yoo and Park, 2015).

With the above research-based findings and theoretical considerations in mind, we sought to implement an integrated approach to the teaching and learning of neuroanatomy and neurophysiology across Motor Speech Disorders (MSD) and Aphasia (APH) coursework in a graduate level SLP program. We chose to integrate neuroanatomy and neurophysiology across two sub-disciplines of SLP that typically discuss this foundational content separately. Our methods considered cognitivism generally and a cognitive theory of multimedia learning specifically in an effort to facilitate horizontal integration and recall of foundational neuroanatomy information. In particular, we designed five narrated lectures around five core subtopics of neuroanatomy and neurophysiology (the brain, brainstem, spinal cord, neuron, and vascular system) to help students' focus on the most relevant conceptual information via the simultaneous presentation of visuals and words paired with narration. Students then engaged in retrieving the conceptual information related to each lecture by completing associated recall questions. Further, students were able to view each narrated lecture at their own pace and stop and start it at their leisure to minimize cognitive load. Efforts to promote vertical integration and transfer of the foundational information were facilitated by students' completion of clinical case questions paired with each sub-topic. Our overall goal was to facilitate these processes early on in both courses so that students would be prepared to connect neuroanatomy and neurophysiology to the assessment and treatment of APH and MSD. To examine the effectiveness of our pedagogical approach, we sought to answer the following research questions:

(1) Does students' ability to identify and describe foundational information (i.e., content), associated with five target neuroanatomy and neurophysiology topic areas (brain, brainstem, spinal cord, neuron, vascular system), improve from after students' pre-course completion of educational modules to following additional case-based activities and discussion in class?

(2) Does student's ability to apply foundational content knowledge to and integrate it with clinical case information associated with five target neuroanatomy and neurophysiology topic area (brain, brainstem, spinal cord, neuron, vascular system) improve from after students' pre-course completion of educational modules to following additional case-based activities and discussion in class?

(3) What are students' perceptions of this integrated learning experience? 


\section{Methods}

Participants. Participants in this study were 58 graduate students in a clinical SLP Master's degree program (Female $=57$, Male $=1$ ) who were enrolled in both APH and MSD in either Spring 2014 or 2015 at Illinois State University. This project was approved by Illinois State University's Institutional Review Board. Participating students signed a consent form granting analysis of their course materials for the purposes of this study. Although, author 1 (L.A.Vinney) was the official instructor of MSD and author 2 (J.M. Harvey) was the official instructor of $\mathrm{APH}$, we co-taught and co-developed the integrated portions of each course described under procedures.

\section{Procedure.}

Pre-course module completion. In order to give students time to interact with content at their own pace and prepare them to apply information to clinical cases at the outset of each course (APH and MSD), participants completed five neuroanatomy and neurophysiology learning modules segmented by topic (i.e., the brain, brainstem, spinal cord, motor unit, vascular system) in the weeks (i.e., winter break) preceding the start of their spring semester (2014 or 2015 depending on cohort). Students had approximately four weeks to complete all five modules.

Module components. Modules included: (1) A narrated lecture discussing the module's main theme (i.e., brain, brainstem, spinal cord, neuron, vascular system); (2) Five to 20 associated recall questions (multiple choice/matching) meant to help students self-assess their recall of content related to each module's narrated lecture; and (3) Two clinical cases in which students were challenged to apply foundational module content towards predicting broad-based deficits or symptoms based on a fictional patient's neurological damage. (See sample case-based questions in Appendix A.) Prior to the first MSD or APH class of the semester, answer keys for the recall questions were released to students online. No sample answers to casebased questions were provided to students prior to the first week of APH and MSD.

Post-module survey. Following pre-course module completion, a post-module survey was disseminated during the first APH or MSD class period of the semester (Appendix B). This survey asked students to indicate their prior experience with module content covered as well as when they completed the modules during their four-week winter break. Students were also asked to indicate why they believed pre-course module completion did or did not facilitated their neuroanatomy and neurophysiology content knowledge or clinical application of that knowledge. 
In-course review of modules. Following pre-course module completion and the post-module survey, each module was augmented in-class across four different course sessions (2 APH and 2 MSD class period) during the first week of the spring semester. We co-taught these four classes in order to emphasize to students that MSD and APH have common core neurophysiology and neuroanatomy underpinnings.

Priming activities. During each of the four class periods, one to two priming activities, associated with content from modules one through five, were presented to students. Each priming activity asked students to answer 5-20 multiple choice and/or matching questions to facilitate student recall of module content. Students first completed these questions individually and then discussed their answers in small groups. Correct answers for each question were then shared by instructors and any questions or confusions were discussed.

Case activities. All students were asked to bring their responses to module case questions to all four co-taught class sessions. During class, students were asked to discuss their case question answers in small groups and then as a whole class. A variety of different answers, representative of the complex nature of each case, were then shared by students. Finally, discussion about how each response did or did not demonstrate integration between clinical case information and neuroanatomy and neurophysiology content then took place.

Student questions. Any time left over, after the completion of module priming and case activities, was devoted to students' general questions about module content and its application. Course period one, two, three, and four typically addressed priming, case activities, and questions related to content from module one (the brain), module two (the brainstem), module 3 (the spinal cord), and modules 4 and 5 (the neuron and the vascular system), respectively.

In-class exam. The first class period (APH or MSD) of the second week of the semester was used to gauge student mastery of this foundational course content via an exam that included case-based questions similar to those completed during pre-course module completion. Each exam case question corresponded to a module theme (brain, brainstem, spinal cord, the neuron, vascular system). (See sample case-based questions in Appendix A.)

Post-exam survey. Immediately after the exam was graded and returned, students completed a survey in either an APH or MSD class period. The survey asked students to reflect on their entire experience with the integrated neuroanatomy and neurophysiology unit (i.e., the pre-course module completion, 
in-class augmentation via activities and discussions, and the culminating exam). Students were specifically asked to indicate why they did or did not believe that this unit served as a basis for further study of neurological speech and communication disorders and to improve their ability to engage in clinical application of content. Suggestions for changes and perceptions of the least and most useful components of the integrated unit were also solicited. (See Appendix $\mathrm{C}$ for post-exam survey questions and Figure 1 for a full timeline of the pedagogical methods detailed here.)

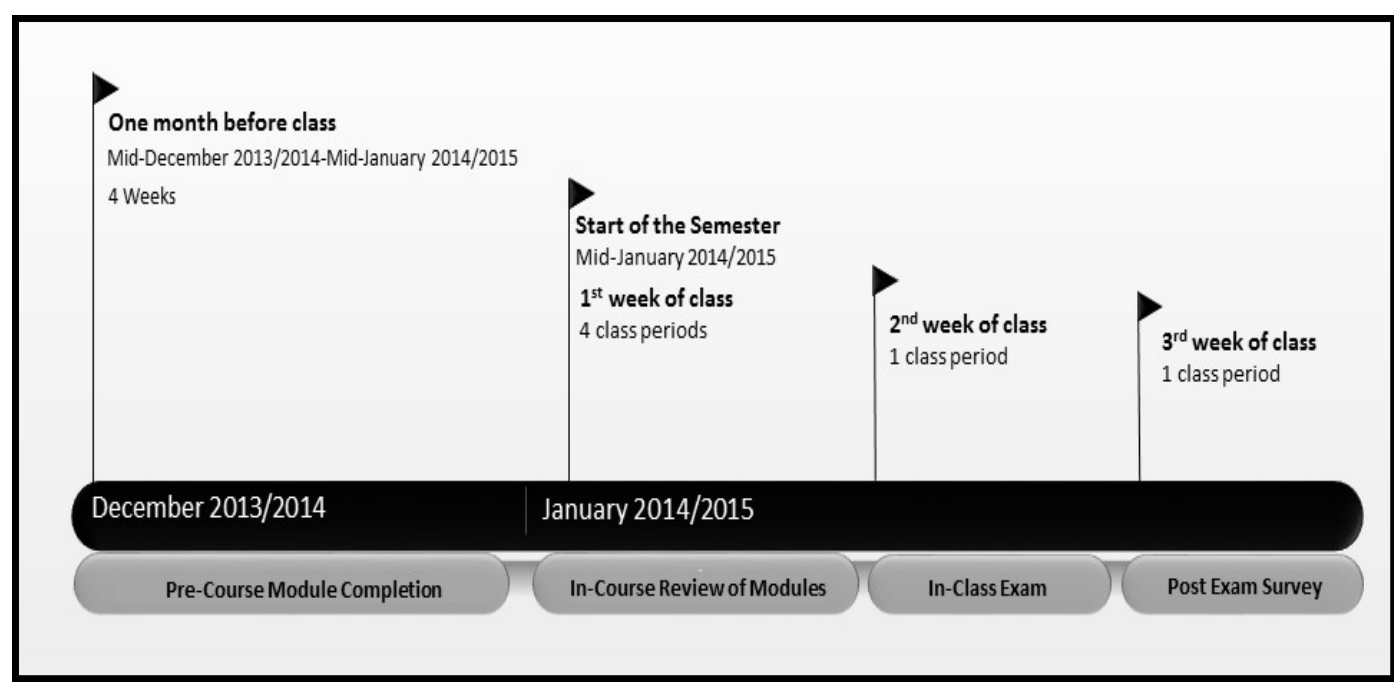

Figure 1: Timeline of pedagogical methods used.

Quantitative. To investigate whether students' ability to identify and describe foundational neuroanatomy and neurophysiology content improved from precourse module completion to the exam, the authors used a rubric tailored to assessing free responses to case-based questions (Appendix D). We scored each case response from one to four across two different categories. For category one, content, a score of one indicated that target foundational content knowledge was not demonstrated in the case response. On the other hand, a score of four indicated that foundational content knowledge was demonstrated throughout the case response. For the second category of our rubric, application and integration, a score of one indicated that case features were incorrectly interpreted leading to inaccurate case conclusions (i.e., predictions about resulting deficits from neurological damage). Further, a score of one indicated that integration between foundational knowledge and case features was not apparent throughout the case response. On the other hand, a score of four in this category indicated that all case features were correctly interpreted leading to accurate case conclusions (i.e., predictions about resulting deficits from neurological damage). Further, a score of four indicated that 
integration between foundational knowledge and case features was apparent throughout the case response.

Students completed two case questions per target topic (brain, brainstem, spinal cord, neuron, vascular system) during pre-course module completion and only one case question per topic (brain, brainstem, spinal cord, neuron, vascular system) during the exam. Thus, the rubric scores for pre-course module case questions were averaged by topic. As a result, one rubric score was generated for both content and application/integration for pre-course module case questions and exam case questions for the topics of the brain, brainstem, spinal cord, neuron and vascular system. We generated rubric scores for each case response separately and then met to discuss any discrepancies in scoring until agreement was reached. Before case questions were scored for the purposes of this study, all identifying information was redacted, by a graduate research assistant, in order to minimize instructor bias and maintain students' confidentiality.

Qualitative. We employed descriptive coding to generally describe students' responses to open-ended survey questions (Appendix B and C) regarding their experiences with the modules and neuroanatomy and neurophysiology unit (Sandalowski, 2000; Saldana, 2013). All student responses were read by the authors and a list of themes were then derived based on student responses. Next, each students' open-ended survey responses were re-read and coded with a theme or themes (Sandalowski, 2000, 2001; Saldana, 2013). Finally, we counted the number of responses that exhibited each theme, by question, to best interpret our findings and identify particular trends (Sandalowski, 2000, 2001; Miller \& Crabtree, 1992). Additionally, student responses regarding when they completed the pre-course modules and their familiarity with the brain, brainstem, spinal cord, neuron, and vascular system were tallied.

\section{Data Analysis}

To determine if rubric-scored content and integration significantly improved from pre to post-assessment by module we conducted a Wilcoxon signed-rank test due to a skewed, non-normal distribution. The critical value for obtaining statistical significance was set at $a=.05$.

\section{Results}

Module Completion. According to the post-module survey of 58 participants, 10 (17\%) completed the pre-course modules during the first one or two weeks of their winter break while $29(50 \%)$ indicated completing the modules during the last week 
or two of their break. Nine participants (16\%) completed the modules throughout their entire break, and 10 (17\%) students did not report when they completed the modules.

Familiarity of Module Topics. Participants also indicated how familiar they were with each module topic on the post-module survey. All participants $(100 \%)$ were familiar with the basic neuroanatomy and neurophysiology detailed in the brain module. Next, participants indicated the greatest familiarity with the brainstem (76\%) followed by the motor unit (72\%) and vascular system (50\%). Participants were least familiar with the spinal cord as only $14 \%$ reported content knowledge in this area.

Gains in Content Knowledge. Participants' rubric-scored content knowledge improved significantly from pre-course module case responses to in-class exam case responses for the target topics of the brainstem (Mdn module $=2, M d n$ exam $=4$ $\mathrm{Z}=-6.027, p=.000, r=-.560)$; the spinal cord (Mdn module $=2.25, M d n$ exam $=4$, $\mathrm{Z}=-4.597, p=.000, r=-.427)$; and the neuron (Mdn module $=1.5$, Mdn exam $=4, \mathrm{Z}$ $=-5.215, p=.000, r=-.484)$. No statistically significant changes were found in content knowledge for the brain (Mdn module=2.5, Mdn exam=3, Z $=-1.918, p=$ $.055, r=.178$ ) or the vascular system (Mdn module $=3$, Mdn exam $=2, \mathrm{Z}=.000, p=$ 1.00, $r=.00)$. See Table 1 for mean content scores for pre-course module case responses and in-class exam cases responses, and the absolute differences between these mean scores by target topic.

\begin{tabular}{|l|c|c|c|c|}
\hline $\begin{array}{l}\text { TARGET } \\
\text { TOPIC }\end{array}$ & $\begin{array}{c}\text { Module Case } \\
\text { Score Means } \\
\text { (Content) }\end{array}$ & $\begin{array}{c}\text { Exam Case } \\
\text { Score Means } \\
\text { (Content) }\end{array}$ & $\begin{array}{c}\text { Mean } \\
\text { Absolute } \\
\text { Difference } \\
\text { (Content) }\end{array}$ & Range \\
\hline Brain & $2.53(.69)$ & $2.86(1.07)$ & $0.34(1.28)$ & $1-4$ \\
\hline Brainstem & $1.97(.70)$ & $3.55(.82)$ & $1.58(1.10)^{*}$ & $1-4$ \\
\hline Spinal Cord & $2.28(.83)$ & $3.26(1.12)$ & $0.98(1.29)^{*}$ & $1-4$ \\
\hline The Neuron & $1.81(.82)$ & $3.12(1.19)$ & $1.31(1.33)^{*}$ & $1-4$ \\
\hline Vascular System & $2.72(.94)$ & $2.29(.92)$ & $0.08(1.67)$ & $1-4$ \\
\hline
\end{tabular}

Table 1: Mean content rubric scores $(1=$ full demonstration of content knowledge; 4=no demonstration of content knowledge) for pre-course module case responses and in-class exam case responses by target topic. Mean absolute difference scores reflect the average change in rubric scores for pre-course module to exam cases responses by target topic. Stars signal a significant change from pre-course module to exam. 
Application and Interpretation of Content. Participants' rubric scored demonstration of application and integration of content knowledge with clinical case information improved significantly from pre-course module to in-class exam completion for the brain (Mdn module $=2.5, M d n$ exam $=3, \mathrm{Z}=-3.377, p=.001, r$ $=-.314)$; the brainstem $(M d n$ module $=2, M d n$ exam $=4, \mathrm{Z}=-5.326, p=.000, r=-$ .495); the spinal cord (Mdn module $=2, M d n$ exam $=3, \mathrm{Z}=-4.208, p=.000, r=-$ .391); and the neuron (Mdn module =1.5, Mdn exam $=4, \mathrm{Z}=-5.454, p=.000, r=$ -.51). No statistically significant differences were found in the application/integration domain from pre-course module to in-class exam completion for the vascular module (Mdn module $=3$, Mdn exam $=2, \mathrm{Z}=.000, p=$ $1.00, r=.00$ ). See Table 2 for mean application/integration scores for pre-course module case responses and in-class exam cases responses, and the absolute differences between these mean scores by target topic.

\begin{tabular}{|c|c|c|c|c|}
\hline $\begin{array}{l}\text { TARGET } \\
\text { TOPIC }\end{array}$ & $\begin{array}{c}\text { Module Case } \\
\text { Score Means } \\
\text { (Integration } \\
\text { \& } \\
\text { Application) }\end{array}$ & $\begin{array}{c}\text { Exam Case } \\
\text { Score Means } \\
\text { (Integration } \\
\& \\
\text { Application) }\end{array}$ & $\begin{array}{c}\text { Mean } \\
\text { Absolute } \\
\text { Difference } \\
\text { (Integration } \\
\text { \& } \\
\text { Application) }\end{array}$ & Range \\
\hline Brain & $2.34(.70)$ & $2.90(.82)$ & $0.55(1.16)^{*}$ & $1-4$ \\
\hline Brainstem & $1.96(.85)$ & $3.33(.94)$ & $1.37(1.40)^{*}$ & $1-4$ \\
\hline Spinal Cord & $2.03(.85)$ & $2.84(1.18)$ & $0.81(1.28) *$ & $1-4$ \\
\hline The Neuron & $1.58(.75)$ & $2.97(1.31)$ & $1.39(1.32)^{*}$ & $1-4$ \\
\hline $\begin{array}{l}\text { Vascular } \\
\text { System }\end{array}$ & $2.29(.92)$ & $2.40(1.43)$ & $0.10(1.76)$ & $1-4$ \\
\hline
\end{tabular}

Table 2: Mean application/integration rubric scores (1=full demonstration of content knowledge; $4=$ no demonstration of content knowledge) for pre-course module case responses and in-class exam case responses by target topic. Mean absolute difference scores reflect the average change in rubric scores for precourse module to exam cases responses by target topic. Stars signal a significant change from pre-course module to exam.

\section{Participant Perceptions.}

Pre-course module completion. All students indicated that completion of the precourse modules facilitated their content knowledge of neuroanatomy and neurophysiology. See Table 3 for the various themes justifying this positive response and the percentage and number of participants who indicated them. 
Approximately $60 \%(n=35)$ of students believed that the modules facilitated clinical application of concepts while $31 \%(n=18)$ of students believed they did not. Five of the 58 students (9\%) believed clinical application was partially supported by the modules. See Table 4 for the various themes indicated by participants to support their responses.

\begin{tabular}{|l|l|}
\hline THEMES & $\begin{array}{l}\text { Number and percentage of } \\
\text { participants indicating } \\
\text { specified theme }\end{array}$ \\
\hline $\begin{array}{l}\text { Facilitated understanding via } \\
\text { comprehensiveness of information }\end{array}$ & $35 / 58(60 \%)$ \\
\hline $\begin{array}{l}\text { Narrated explanations and visuals supported } \\
\text { content knowledge }\end{array}$ & $15 / 58(26 \%)$ \\
\hline $\begin{array}{l}\text { Self-paced nature of modules facilitated } \\
\text { understanding }\end{array}$ & $10 / 58(17 \%)$ \\
\hline
\end{tabular}

Table 3: Common themes justifying why participants $(n=58)$ felt pre-course module completion facilitated content knowledge of neuroanatomy and neurophysiology.

\begin{tabular}{|c|c|}
\hline THEMES & $\begin{array}{l}\text { Number and percentage of } \\
\text { participants indicating } \\
\text { specified theme }\end{array}$ \\
\hline \multicolumn{2}{|l|}{$\begin{array}{l}\text { Justification as to why application of } \\
\text { concepts was facilitated }\end{array}$} \\
\hline $\begin{array}{l}\text { Case activities facilitated localization of deficits } \\
\text { based on foundational knowledge }\end{array}$ & $18 / 35(51 \%)$ \\
\hline $\begin{array}{l}\text { Clinical examples within narrated lectures } \\
\text { facilitated application }\end{array}$ & $9 / 35(26 \%)$ \\
\hline \multicolumn{2}{|l|}{$\begin{array}{l}\text { Justification as to why application of } \\
\text { concepts was not facilitated }\end{array}$} \\
\hline $\begin{array}{l}\text { Need for additional time with content and } \\
\text { instructors' immediate feedback for application } \\
\text { to occur }\end{array}$ & $16 / 18(89 \%)$ \\
\hline $\begin{array}{l}\text { Limited opportunities to apply content during } \\
\text { module completion }\end{array}$ & $9 / 18(50 \%)$ \\
\hline $\begin{array}{l}\text { Focus on recall rather than application when } \\
\text { learning information for the first time }\end{array}$ & $4 / 18(22 \%)$ \\
\hline
\end{tabular}

Table 4: Common themes justifying why participants felt pre-course module completion facilitated $(n=35)$ or did not facilitate $(n=18)$ clinical application of concepts. 
Full integrated neuroanatomy and neurophysiology unit. A majority (91\%, $\mathrm{n}=53$ ) of participants indicated their belief that the entire integrated neuroanatomy and neurophysiology unit (i.e., the pre-course module completion, in-class augmentation via activities and discussions, and the culminating exam) served as a basis for further study of neurological speech and communication disorders while only $9 \%(n=5)$ of students believed it did not or only partially did. See Table 5 for the various themes indicated by participants to support their responses.

\begin{tabular}{|l|l|}
\hline THEMES & $\begin{array}{l}\text { Number \& percentage of } \\
\text { participants indicating } \\
\text { specified theme }\end{array}$ \\
\hline $\begin{array}{l}\text { Justification as to why the integrated unit } \\
\text { added to knowledge base }\end{array}$ & \\
\hline $\begin{array}{l}\text { No neurology course in undergraduate } \\
\text { coursework made this experience crucial as a } \\
\text { basis for further study }\end{array}$ & $4 / 53(8 \%)$ \\
\hline $\begin{array}{l}\text { Provided preparation for both aphasia and } \\
\text { motor speech disorders coursework }\end{array}$ & $43 / 53(81 \%)$ \\
\hline $\begin{array}{l}\text { Improved understanding of the relationship } \\
\text { between neurological structures and functions }\end{array}$ & $13 / 53(25 \%)$ \\
\hline $\begin{array}{l}\text { Justification as to why the integrated unit } \\
\text { did not add to knowledge base }\end{array}$ & \\
\hline Poor retention of content due to fast pace & $2 / 5(40 \%)$ \\
\hline Content too complex/difficult & $1 / 5(20 \%)$ \\
\hline
\end{tabular}

Table 5: Common themes justifying why participants felt the integrated neuroanatomy and neurophysiology unit either added $(n=53)$ or did not add $(n=5)$ to their knowledge base.

Approximately 67\% (n=39) of participants believed that the entire integrated neuroanatomy and neurophysiology unit facilitated clinical application of concepts while $33 \%(n=19)$ of students believed that it did not or only partially supported application. See Table 6 for the themes indicated to support responses.

Participants also indicated which components of this experience supported their learning most and which supported their learning least. The most helpful components mentioned included the narrated lecture $(48 \%, \mathrm{n}=28)$, in-class discussion of concepts and cases $(48 \%, \mathrm{n}=28)$, studying for and taking the exam $(24 \%, \mathrm{n}=14)$, coverage of specific content areas that were new or for which students had not achieved previous mastery $(21 \%, \mathrm{n}=12)$, case application activities $(19 \%$, $\mathrm{n}=11)$, module multiple choice/ matching questions $(19 \%, \mathrm{n}=11)$, the self-paced nature of modules $(9 \%, \mathrm{n}=5)$, and in-class priming activities $(7 \%, \mathrm{n}=4)$. 


\begin{tabular}{|c|c|}
\hline THEMES & $\begin{array}{l}\text { Number \& percentage of } \\
\text { participants indicating } \\
\text { specified theme }\end{array}$ \\
\hline \multicolumn{2}{|l|}{$\begin{array}{l}\text { Justification as to why individual components of } \\
\text { the integrated unit added to knowledge base }\end{array}$} \\
\hline $\begin{array}{l}\text { Case activities facilitated the integration of } \\
\text { foundational knowledge with practical scenarios }\end{array}$ & $10 / 39(26 \%)$ \\
\hline $\begin{array}{l}\text { Improved knowledge of neuroanatomy and } \\
\text { neurophysiology assisted with higher-level } \\
\text { application of content }\end{array}$ & $32 / 39(82 \%)$ \\
\hline \multicolumn{2}{|l|}{$\begin{array}{l}\text { Justification as to why individual components of } \\
\text { the integrated unit did not add to students' } \\
\text { knowledge base }\end{array}$} \\
\hline $\begin{array}{l}\text { Limited opportunities to apply content with greater } \\
\text { focus on foundational knowledge }\end{array}$ & $8 / 19(42 \%)$ \\
\hline $\begin{array}{l}\text { Inadequate background knowledge prior to } \\
\text { experience made application difficult }\end{array}$ & $2 / 19(11 \%)$ \\
\hline $\begin{array}{l}\text { Clinical application requires additional time and } \\
\text { experience }\end{array}$ & $15 / 19(79 \%)$ \\
\hline
\end{tabular}

Table 6: Common themes justifying why participants felt foundational experience facilitated $(n=39)$ or did not facilitate $(n=19)$ clinical application of concepts.

The least helpful components mentioned included completing the application activities independently without instructor guidance and immediate feedback (33\%, $\mathrm{n}=19$ ), class discussion's focus on application (i.e. case questions) before perceived content mastery $(16 \%, \mathrm{n}=9)$, and logistical aspects of the entire experience $(53 \%$, $\mathrm{n}=31$ ) including its rapid pace, the need to complete pre-course modules over winter break, and technological difficulties with watching and listening to the narrated module lectures.

\section{Discussion}

The current study examined the effects of horizontally integrating foundational curriculum neuroanatomy with neurophysiology across two medically-based SLP courses, MSD and APH, with a specific focus on facilitating vertical integration and transfer of this foundational information with clinical cases. Findings indicated that students' responses to case questions, focused on the brain, brainstem, spinal cord, and neuron, significantly improved both in terms of application/integration and content knowledge from pre-course module to in-class exam completion. In particular, we designed an integrated and coordinated pedagogical approach which sought to maximize student recall of neuroanatomy and neurophysiology concepts through narrated multimedia lectures followed by associated recall questions, and 
promoted transfer of this foundational information to clinical cases. Our class discussion of case questions and recall-based questions provided appropriate feedback for students to self-evaluate and calibrate their knowledge to further aid in both cognitive processes.

For content knowledge, significant gains, with effect sizes ranging from medium to large, were found for the brainstem (large), the spinal cord (medium), and the neuron (medium). For application and integration, significant gains, with effect sizes also ranging from medium to large, were found for the brain (medium), the brainstem (large), the spinal cord (medium), and the neuron (large). The brain and the vascular system were the only content areas for which case responses did not significantly improve for content knowledge. This lack of growth in content knowledge for the brain, may be related to students' unanimous self-reported familiarity with this area $(100 \%)$. It is possible that students were already at a ceiling in this area such that our methods did not result in a great deal of improvement. That being said, students did significantly improve in their application and integration of knowledge in this content area, which may reflect that their previous exposure to information related to the brain was focused more on recall and less on case-based application. On the other hand, a lack of familiarity with the vascular system may have resulted in limited growth in content knowledge and its application and integration with cases (50\% of students indicated little to no previous experience with this area). That being said, $86 \%$ of students indicated a lack of familiarity with the spinal cord and significant gains were made in relationship to this topic. Thus, an alternative explanation for this negative finding may be related to when students completed the vascular system module, which was the last of the five modules completed pre-course. Fifty percent of students completed pre-course modules during the last week to two weeks of their winter break. Thus, it is possible that they may have rushed through this module, and poor content retention, insufficient for higher-level application may have resulted.

In their post-module survey, students overwhelming indicated growth in their knowledge and understanding of neuroanatomy and neurophysiology concepts. They attributed this growth to the comprehensive nature of the modules, narrated explanations and visuals, and self-paced nature of this portion of the experience which speaks directly to some of the multimedia components that typically lead to improved recall of knowledge (Mayer, 2002, 2009; Mayer \& Moreno, 2003). Further, while $60 \%$ of students believed that their clinical application of neuroanatomy and neurophysiology concepts was aided by independent pre-course module completion, due to the case activities and clinical examples integrated within lecture narrations, approximately a third of students felt that this portion of the experience did not facilitate application. These students generally indicated the 
need for more time with the content and immediate feedback from instructors, particularly in relationship to case-based questions. Many also noted their belief that, because narrated lectures were the largest component of each module, they did not have sufficient opportunities to apply content. Other students suggested that they were attempting to master content for so much new information that they were unable to focus on applying it.

In their post-exam survey, there was a slight decline in the number of students who believed the entire integrated neuroanatomy and neurophysiology unit had facilitated their foundational knowledge (i.e., $100 \%$ of students expressed this belief post-module while only $91 \%$ expressed this following the complete experience). Most students noted that their content knowledge was facilitated, particularly if they had not had a neurology course during undergraduate study. Other students expressed the feeling that this experience prepared them for future content and application in APH and MSD, particularly by improving their understanding of neurological structure and functions. The few students who did not feel this experience led to overall gains in content knowledge indicated that they were unable to retain the content due to its complexity, the amount of it, and the pace with which it was to be acquired. In terms of application, more students felt they had gained the ability to apply content clinically after the entire experience $(67 \%)$ as opposed to post-module $(60 \%)$ due to further discussion of case activities and their increased mastery of the foundational knowledge by the first week of spring semester. However, other students believed their application of core content was not facilitated via the entire experience. Their justifications for this impression were like those provided by students who had a similar impression following independent pre-course module completion. Specifically, students indicated feeling like they had had limited chances to practice applying content and inadequate neuroanatomy and neurophysiology background knowledge; thus, they were primarily focused on content mastery rather than application. Some students felt that they were beginning to develop the ability to apply foundational information, but required additional time and experience before competent application of content would be possible.

\section{General Implications}

The pedagogical innovation described in this paper has several implications that may inform future SLP graduate educational programs. In particular, this particular strategy was an efficient way to expose students to neuroanatomy and neurophysiology content, foundational to two different courses without redundancy (i.e., covering the same foundational topics individually within each course); by asking students to complete modules independently during their winter 
break, we hoped they would have sufficient exposure to content and some practice with application activities before APH and MSD even began. While students' perceptions as to whether they were prepared to do this were mixed, the majority did indicate that the modules alone prepared them to apply content during the first week of class and clearly students' growth in foundational knowledge and its application to clinical cases was significantly aided by such scaffolding. Because application of foundational knowledge was the immediate focus of both APH and MSD during the first week of classes, an exam assessing both content and application/integration of content was delivered in the second week of class, allowing for coverage of disorder-specific content to follow soon after.

Likewise, by starting these courses in an integrated manner, students' attention was brought to the common foundational underpinnings of APH and MSD. As a result, an understanding of how neurological damage may result in both classes of disorders was made clear and further set the stage for integration across these courses. Specifically, following this foundational experience more opportunities for horizontal integration and vertical integration were provided to students. These opportunities included an integrated APH and MSD cranial nerve exam and language screening lab and culminating experience in which students were tasked with differentially diagnosing and formulating treatment recommendations for fictional patients with both an aphasia and motor speech disorders.

\section{Study Limitations}

This study had several limitations. First, it is not clear which variables of this pedagogical innovation contributed to the significant learning gains found for four of the five modules in terms of content knowledge and application. Students' growth in content mastery and integration/application of content knowledge with case features may have been related to a specific aspect of the entire neuroanatomy and neurophysiology unit, outside influences (i.e., the amount they studied for the exam), or a combination of components. Further, although this study examined integration of foundational information across classes it did not specifically compare a lack of integration between core foundational content to integration. In particular, there was no comparison control group that did not receive the integrated foundational content described here. Future work might compare these two different models during students' exposure to core foundational content and across integrated SLP coursework (particularly as disorder-based content is addressed in detail). Finally, our qualitative methods and rubric-scoring were subjective in nature, as interpretations of student responses were integral to the outcomes reported here. That being said, we would argue, that these methods are ecologically 
valid and more akin to how learning and instruction would be evaluated in an everyday classroom environment.

\section{Considerations for Curriculum}

The foundational integrated experience described in the paper was borne out of Illinois State University's speech-language pathology faculty noticing SLP masters students' difficulty integrating course content with clinical application as well as content within and between classes (i.e., vertical and horizontal integration). Further, efficiently exposing students to foundational neurological content (applicable to both APH and MSD) regardless of prior coursework was a necessity in our SLP masters program. Still, students noted several challenges with this experience including: (1) The demands it placed on student's time; (2) Lack of immediate feedback from instructors during independent module completion; (3) Difficulty mastering complex content for application due to time constraints or minimal prior background knowledge; and (4) The timing of a portion of this experience over students' winter break.

To address the challenges reported by students as well as achieve vertical and horizontal integration across the entire SLP curriculum, our department used data from this and other integrated projects (Friberg \& Harbers, 2016) as a basis for a full curriculum re-design. Our new curriculum is structured such that course content is integrated across courses (i.e., instead of disorder-based courses, integration occurs across the curriculum). As a result of this project, specifically, the instructors and rest of the CSD department at Illinois State University have designed an advanced neurological course that will be centrally focused on clinical cases related to the brain, brainstem, spinal cord, neuron, and vascular system. This course will address how damage to these areas together and alone can lead to an array of cognitive, motor, and sensory deficits resulting in communication and swallowing disorders. It is hoped that the challenges that students encountered with this experience will be remedied by providing them with an entire course in which they will be given opportunities and time to master content and apply that content to clinical cases with additional instructor guidance and immediate feedback. A number of methods for assessing this new curriculum, as well as this new course, have been developed.

\section{Reflection from Instructors' Perspective}

Integrating curriculum both horizontally and vertically requires close coordination between instructors. In particular, the instructors, had to spend ample amounts of time developing the coordinated content not only related to these results, but the 
additional integrated opportunities provided throughout the semester. Students were also not used to this model of instruction so initial buy-in to the integrated experience, particularly because it was largely independent, was a challenge. To help facilitate student buy-in, we provided them with advanced notice (in the first week of their fall semester) about pre-course modules and the expectation that they would be completed over their winter break. We also justified the value of vertical and horizontal integration when initially introducing this experience to students and throughout their in-class experience in MSD and APH. We anticipate that our whole-sale curriculum revision will be met with similar challenges, but our department is up for these challenges given the potential rewards in students' clinical knowledge and application.

\section{Conclusions}

This study explored integration of foundational neuroanatomy and neurophysiology content for graduate APH and MSD coursework. Students generally believed that their integrated experience improved their content knowledge (recall) and ability to clinically apply (transfer) that knowledge. Further, rubric-evaluated gains in content and application/integration, as reflected in student responses to case-based questions, significantly improved for four out of five content areas covered. Results support continued horizontal and vertical integration in SLP curriculum.

\section{References}

Alsaggaf, S., Ali, S. S., Ayuob, N. N., Eldeek, B. S., \& El-Haggagy, A. (2010). A model of horizontal and vertical integration of teaching on the cadaveric heart. Annals of Anatomy, 192(6), 373-377.

Ambrose, S. A., Bridges, M. W., DiPietro, M., Lovett, M. C., \& Norman, M. K. (2010). How learning works: 7 research-based principles for smart teaching. San Francisco, CA: Jossey- Bass.

Anderson, L. W., \& Krathwohl, D. R. (2001). A taxonomy for learning, teaching, and assessing: A revision of Bloom's taxonomy of educational objectives. New York, NY: Longman.

Bloom, B. S. (1956). Taxonomy of educational objectives. Handbook I: Cognitive domain. New York, NY: Longman.

Clark, R., \& Harrelson, G.L (2002). Designing instruction that supports cognitive learning processes. Journal of Athletic Training, 37(4 suppl.), S-152-S-159.

Cooper, P. A. (1993). Paradigm Shifts in Designed Instruction: From Behaviorism to Cognitivism to Constructivism. Educational technology, 33(5), 12-19.

Council for Clinical Certification in Audiology and Speech-Language Pathology of the American Speech-Language-Hearing Association. (2013). 2014 Standards for 
the Certificate of Clinical Competence in Speech-Language Pathology. Retrieved from http://www.asha.org/Certification/2014-Speech-LanguagePathology-Certification-Standards/.

Ertmer, P. A., \& Newby, T. J. (1993). Behaviorism, cognitivism, constructivism: Comparing critical features from an instructional design perspective. Performance improvement quarterly, 6(4), 50-72.

Fink, L. D. (2013). Creating significant learning experiences: An integrated approach to designing college courses. San Francisco, CA: Jossey-Bass.

Friberg, J. C. \& Harbers, H. (2016). Encouraging cross-curricular integration in communication sciences and disorders. The Journal of Research and Practice in College Teaching, 1(1), 1-14.

Harden, R. M. (2000). The integration ladder: A tool for curriculum planning and evaluation. Medical Education, 34, 551-557.

Harman, T., Bertrand, B., Greer, A., Pettus, A., Jennings, J., Wall-Bassett, E., \& Babatunde, O. T. (2015). Case-based learning facilitates critical thinking in undergraduate nutrition education. Journal of the Academy of Nutrition \& Dietetics, 115(3), 378-388.

Hassan, S. (2013). Concepts of vertical and horizontal integration as an approach to integrated curriculum, Education in Medicine Journal, 5(4), e1-e5.

Holland, B., Roberts, K., Vanstewart, A., \& Wright, J. (1994). Life-span geriatric interdisciplinary curriculum for preparing future health-care professionals. Educational Gerontology, 20(3), 231-239.

Howard, K. M., Stewart, T., Woodall, W., Kingsley, K., \& Ditmyer, M. (2009). An integrated curriculum: Evolution, evaluation, and future direction. Journal of Dental Education, 73(8), 962-971.

Jackson, C. A., \& Woosley, J. D. (2009). A different set of classrooms: Preparing a new generation of clinicians, Forum on Public Policy, 1, 1-10.

Kantar, L. D., \& Massouh, A. (2015). Case-based learning: What traditional curricula fail to teach. Nurse Education Today, 35(8), e8-e14.

Krockenberger, M., Bosward, K., \& Canfield, P. (2007). Integrated Case-Based Applied Pathology (ICAP): A diagnostic-approach model for the learning and teaching of veterinary pathology. Journal of Veterinary Medical Education, 34(4), 396-408.

Leahy, M. M., McTiernan, K., Smith M. M., Sloane P., Walsh I. P., Walshe M., \& Ni Cholmain, C. (2010): Foundation studies in education for therapy practice: curriculum updating. Folia Phoniatrica Et Logopaedica, 65(2), 255-259.

Loghmani, M. T., Bayliss, A. J., Strunk, V., \& Altenburger, P. (2011). An integrative, longitudinal case-based learning model as a curriculum strategy to enhance teaching and learning. Journal of Physical Therapy Education, 25(2), 42-50 $9 \mathrm{p}$.

Malik, A. S., \& Malik, R. H. (2011). Twelve tips for developing an integrated curriculum. Medical Teacher, 33(2), 99-104. 
Martin, K., Bessell, N. J., \& Scholten, I. (2014). The perceived importance of anatomy and neuroanatomy in the practice of speech-language pathology. Anatomical Sciences Education, 7(1), 28-37.

Mathisen, B., Yates, P., \& Crofts, P. (2011). Palliative care curriculum for speechlanguage pathology students. International Journal of Language \& Communication Disorders, 46(3), 273-285.

Mayer, R. E. (1997). Multimedia learning: Are we asking the right questions? Educational psychologist, 32(1), 1-19.

Mayer, R. E. (2002). Multimedia learning. Psychology of learning and motivation, $41,85-139$.

Mayer, R. E. (2009). Multimedia Learning. New York, NY: Cambridge University Press.

Mayer, R. E., \& Moreno, R. (2003). Nine ways to reduce cognitive load in multimedia learning. Educational psychologist, 38(1), 43-52.

Meilijson, S., \& Katzenberger, I. (2015). A clinical education program for speechlanguage pathologists applying reflective practice, evidence-based practice and case-based learning. Folia Phoniatrica Et Logopaedica, 66(4), 158-163.

Miller, W. L. , \& Crabtree, B. F. (1992). Primary care research: A multimethod typology and qualitative road map. In B. F. Crabtree \& W. L. Miller (Eds.), Doing qualitative research (pp. 3-28). Newbury Park, CA: Sage.

Saldana, J. (2013). The coding manual for qualitative researchers $\left(2^{\text {nd }}\right.$ ed.). Los Angeles: Sage.

Sandelowski, M. (2000). Whatever happened to qualitative description? Research in Nursing and Health, 23(4), 334-340.

Sandelowski, M. (2001). Real qualitative researchers do not count: The use of numbers in qualitative research. Research in Nursing and Health, 24(3), 230-240.

Sankowsky, D. (1998). Two pathways to instructional delivery: Distinguishing between the discipline-based and development-based paradigms. Journal of Management Education, 22(3), 269-284.

Spady, W. (1994). Choosing outcomes of significance. Educational Leadership, 51(6), $18-22$.

Trommelen, R. D., Hebert, L., \& Nelson, T. K. (2014). Impact on physical therapy and audiology students of an interprofessional case-based learning experience in education of vestibular disorders. Journal of Allied Health, 43(4), 194-200.

Wilson, H.F. (2002) Gifts from the web: Problem-based learning. Perspectives on Issues in Higher Education, 5, 5-8.

Yoo, M., \& Park, J. (2015). Effect of case-based learning on the development of graduate nurses' problem-solving ability. Nurse Education Today, 34(1), 4751 . 


\section{Appendix A: Sample Case-Based Questions}

\section{Brain Module}

Meredith Mark is a speech-language pathologist at Mercy West acute trauma center. She received a consult for Michael McCracken, a 62-year-old male, who was admitted due to severe changes in behavior. Initial imaging indicated there was a mass rostral to the midbrain and ventral to the hypothalamus. What types of sensory and motor issues do you hypothesize will be observed?

\section{Brainstem Module}

Gabe Gates is 13 years old. He likes to play football every Saturday with the neighborhood kids. Gabe wears his football gear, including a helmet, shoulder and chest pads, and shin guards. In the second half of the game, Gabe plays the position of quarterback for the first time. Gabe receives the ball and runs towards the opposing end zone. The opposing team's defense crowds Gabe, and in the process of tackling him, Gabe is flipped over, landing on his shoulders, with two defensive players landing on top of him. The angle and force of the tackle crushes his spinal cord at $\mathrm{C} 4$.What motor and sensory deficits will this injury cause?

\section{Spinal Cord Module}

Tom Tinker is taking his son, Taylor Tinker, to the pediatrician. He recently noticed that Taylor is demonstrating decreased sensation. Upon examination, the physician suspects spina bifida occulta. This condition causes incomplete development of the synapse and muscular innervation during embryologic development. How can incomplete development of neurons and neuronal synapses, like Taylor's case, affect the transportation of motor and sensory information?

\section{Neuron Module}

Mr. Scott is a 70 year old male diagnosed with stage two Parkinson's disease. Parkinson's disease result in the death of neurons in the basal ganglia that produce the neurotransmitter dopamine. If a neurotransmitter like dopamine is damaged, what happens in the synapse? What might be a resulting physical symptom of the damage for this example?

\section{Vascular system Module}

Kyle Kanner is a 72-year old female. She has been admitted to the hospital following a cerebral vascular accident. Ms. Kanner has a history of high blood pressure, diabetes, and recently underwent leg surgery. She is retired and lives with her 45-year old daughter. Her daughter reports Ms. Kanner is very physically active. Initial neurological imaging has noted damage to the left lateral aspect of the frontal and temporal lobes. Further, notes from the neurologist document that 
the blood clot had a sudden onset within this vascular area. What type of stroke did Kyle manifest? What types of deficits will she likely demonstrate?

\section{Appendix B: Post-Module Survey}

1. How and when did you complete the modules? (Did you complete all modules at once? Did you work on it a little at a time?)

2. Please describe concepts in the modules with which you were familiar.

3. Please describe concepts in the modules with which you were unfamiliar.

4. Do you feel the modules assisted in your foundational content knowledge of neuroanatomy and neurophysiology? If so, how? If not, why?

5. Do you feel the modules enhanced your clinical application of concepts? If so, how? If not, why?

6. What changes would you suggest to the modules?

\section{Appendix C: Post-Exam Survey}

1. Now that you have completed the entire integrated neuroanatomy and neurophysiology unit (modules, in class lecture, assignments, and exam), do you feel this unit has added to your foundational content knowledge for further study of neurological disorders in speech pathology? If so, how? If not, why?

2. Do you feel this unit facilitated clinical application of concepts? If so, how? If not, why?

3. Which components of this unit (modules, in class discussion, activities, or lecture, assignments, or exam) did you find most helpful?

4. Which components of this unit (modules, in class discussion, activities, or lecture, assignments, or exam) did you find least helpful?

5. What changes would you suggest to this experience? 
Appendix D: Clinical Case Response Rubric

\begin{tabular}{|l|l|l|l|l|}
\hline CATEGORY & $\begin{array}{l}\text { Exceeds } \\
\text { Expectations } \\
\mathbf{4})\end{array}$ & $\begin{array}{l}\text { Meets } \\
\text { Expectations } \\
\mathbf{( 3 )}\end{array}$ & $\begin{array}{l}\text { Marginal } \\
\mathbf{( 2 )}\end{array}$ & $\begin{array}{l}\text { Unacceptable } \\
\mathbf{( 1 )}\end{array}$ \\
\hline Content & $\begin{array}{l}\text { Foundational } \\
\text { content } \\
\text { knowledge is } \\
\text { fully } \\
\text { demonstrated. }\end{array}$ & $\begin{array}{l}\text { Foundational } \\
\text { content } \\
\text { knowledge is } \\
\text { mostly } \\
\text { demonstrated. }\end{array}$ & $\begin{array}{l}\text { Foundational } \\
\text { content } \\
\text { knowledge is } \\
\text { minimally } \\
\text { demonstrated }\end{array}$ & $\begin{array}{l}\text { Foundational } \\
\text { content } \\
\text { knowledge is } \\
\text { not } \\
\text { demonstrated. }\end{array}$ \\
\hline $\begin{array}{l}\text { Application } \\
\text { Integration }\end{array}$ & $\begin{array}{l}\text { All case } \\
\text { information is } \\
\text { interpreted } \\
\text { correctly and } \\
\text { integrated with } \\
\text { foundational } \\
\text { content } \\
\text { knowledge. } \\
\text { All } \\
\text { conclusions } \\
\text { are accurate. }\end{array}$ & $\begin{array}{l}\text { Most case } \\
\text { information } \\
\text { is interpreted } \\
\text { correctly and } \\
\text { integrated } \\
\text { with } \\
\text { foundational } \\
\text { content } \\
\text { knowledge. } \\
\text { Most } \\
\text { conclusions } \\
\text { are accurate. }\end{array}$ & $\begin{array}{l}\text { Case } \\
\text { information is } \\
\text { largely } \\
\text { interpreted } \\
\text { incorrectly } \\
\text { and generally } \\
\text { not integrated } \\
\text { with } \\
\text { foundational } \\
\text { content } \\
\text { knowledge. } \\
\text { Most } \\
\text { conclusions } \\
\text { are not } \\
\text { accurate. }\end{array}$ & $\begin{array}{l}\text { information is } \\
\text { not interpreted } \\
\text { correctly or } \\
\text { integrated with } \\
\text { foundational } \\
\text { content } \\
\text { knowledge. }\end{array}$ \\
& $\begin{array}{llll}\text { All conclusions } \\
\text { are inaccurate. }\end{array}$ \\
\hline
\end{tabular}

